\title{
Dinámica y transformación del espacio periurbano en la ciudad de Formosa, Argentina
}

\author{
Dynamics and transformation of the periurban space in the city of Formosa, \\ Argentina
}

\author{
René Arnaldo Ruiz \\ renearuizz@gmail.com \\ Departamento de Geografía. Facultad de \\ Humanidades. Universidad Nacional de Formosa, \\ Argentina
}

Jorge Alfredo Albero

jaalberto1971@gmail.com

Centro de Geociencias Aplicadas. Universidad

Nacional del Nordeste, Argentina

\section{María Beatriz Romero \\ romerobeatriz64@hotmail.com \\ Departamento de Geografía. Facultad de \\ Humanidades. Universidad Nacional de Formosa, \\ Argentina}

Recepción: 30 Mayo 2021

Aprobación: 06 Septiembre 2021

Publicación: 01 Noviembre 2021

Cita sugerida: Ruiz, R. A., Albero J. A. y Romero, M. B. (2021). Dinámica y transformación del espacio periurbano en la ciudad de Formosa, Argentina. Geograficando, 17(2), e102. https://doi.org/10.24215/2346898Xe102

\begin{abstract}
Resumen: La expansión de la mancha urbana de la ciudad de Formosa sobre el territorio ha presentado un desarrollo difuso que se ha profundizado en los últimos años hacia la periferia con predominio residencial. El sector suroeste se destaca al presentar espacios con diferentes formas de producción habitacional y vacíos urbanos o territorios con riesgo hídrico por sus condicionantes naturales, situación que ha generado una importante fragmentación física y social. En el presente artículo se indaga en los cambios que se observan en el espacio periurbano de la ciudad de Formosa a partir de identificar las transformaciones de usos del suelo en los primeros veinte años del siglo XXI. Para ello se emplea como metodología el análisis cartográfico y documental, complementado con el trabajo de campo y el procesamiento de la información en gabinete.
\end{abstract}

Palabras clave: Urbanización, Periurbano, Usos del suelo, Residencial.

\begin{abstract}
The expansion of the urban sprawl of the city of Formosa over the territory has presented a diffuse development that has deepened in recent years towards the periphery with a residential predominance. The southwest sector in particular presents spaces with different forms of housing production and urban vacuums or territories with water risk due to its natural conditions, a situation that has generated an important physical and social fragmentation. This article delves into the changes observed in the peri-urban space of the city of Formosa by identifying the transformations of land use in the first twenty years of the 21 st century, using cartographic and documentary analysis as a methodology, complemented by field work and desk research for information processing.
\end{abstract}

Keywords: Urbanization, Peri-urban, Land use, Residential.

\section{A) INTRoducción}

La dinámica y transformación territorial en una ciudad se desarrolla a través de un proceso en el tiempo, en el cual la acción antrópica constituye un agente de cambio en la estructura socioespacial. Para entender dichas transformaciones territoriales es necesario tener en cuenta la producción del espacio, en la que la coyuntura histórica juega una forma de materializar el rol del Estado sobre los procesos de construcción y regulación del territorio (Blanco, 2015). 
En relación con este planteo, Santos (2000) entiende la construcción territorial de una ciudad a partir de dos elementos: la continuidad territorial entre lugares adyacentes (horizontalidad) y la articulación de lugares discontinuos mediante redes. Como repuesta a esta realidad sobre el territorio, Reese (2006) insiste en que la planificación es una plataforma de despliegue de estrategias generales de desarrollo urbano que permiten la puesta en marcha de proyectos de actualización de los reglamentos urbanísticos.

También expone con preocupación que las nuevas formas de expansión fragmentada de las ciudades y de urbanización de espacios rurales y naturales responden a la operación de lógicas muy diferentes (Reese, 2006). El desarrollo urbano en forma difusa trae como consecuencia un costo en infraestructura y en el medio ambiente, ya que se consume mayor espacio y existe una considerable dependencia de algún medio de movilidad (automóviles, autobuses, motos, bicicletas). Frediani (2009) considera que la ciudad dispersa se caracteriza por el uso extensivo del territorio y se convierte en una ciudad para transitar y no para vivir.

La expansión urbana generada por la dinámica de crecimiento de la ciudad hacia estos espacios periurbanos provoca transformaciones sobre el ambiente natural, debido al aumento de la franja urbana sobre la rural, lo que trae como resultado la modificación de los usos del suelo. Los sistemas periurbanos crecen sobre el ámbito rural, por la expansión de las márgenes de las ciudades en forma de anillos o por la extensión de corredores, con una compleja interfaz de construcciones edilicias con ambientes naturales y agropecuarios (Alberto, 2004). Para Feito y Barsky (2020), el concepto de periurbano refiere a un territorio de borde sometido a procesos sociales y económicos relacionados con la valorización capitalista del espacio, como consecuencia de la incorporación real o potencial de nuevas tierras a la ciudad. Además, puede reconocerse el periurbano como frontera transicional entre campo y ciudad, pero también como escala intermedia entre una más netamente urbana y otra netamente rural (Benedetti, 2020).

La crisis económica que vivió la Argentina en el año 2001 impactó de manera negativa en la producción del hábitat urbano, ya que limitó el acceso a la vivienda digna para los sectores populares. A partir del año 2002, debido a los cambios macroeconómicos, se plantean políticas de mercado y de desarrollo urbano que influyeron en el cambio de paradigma sobre los problemas urbanos. En respuesta a esta situación, el Gobierno Nacional presentó el "Plan Argentina 2016 - Política y Estrategia Nacional de Desarrollo y Ordenamiento Territorial”, en el cual se propone la construcción de una Argentina equilibrada, integrada, sustentable y socialmente justa, y con el compromiso de proporcionar apoyo técnico y orientación metodológica a los Organismos Provinciales y Municipales encargados de la planificación urbana.

En el mismo período, por influencia de las políticas de Estado antedichas y del mercado inmobiliario presente en este fenómeno, la ciudad de Formosa (Argentina) experimentó un elevado proceso de urbanización sobre áreas rurales circundantes, lo que dio lugar a una diversidad de usos del suelo, pero con notorio predominio del uso residencial. Dicho crecimiento responde al aumento de la población en las últimas décadas: en el año 2001, la ciudad contaba con 198.074 habitantes mientras que en 2010 ascendía a 222.226 (INDEC, 2001, 2010). Este incremento se ve reflejado en la ocupación espacial del territorio con servicios y nuevas edificaciones entre un $35 \%$ y un $40 \%$, del año 2000 al 2020, lo que dio lugar a usos del suelo con fines urbanos y consolidó nuevos espacios periurbanos que responden a un modelo de expansión difusa.

En relación con lo expuesto, el trabajo se propone analizar los cambios en la estructura territorial del espacio periurbano de la ciudad de Formosa, para identificar las transformaciones en el uso del suelo que se vienen registrando en el sector suroeste (SO) entre los años 2000 y 2020. Además, se pretende caracterizar la configuración de la expansión y la densificación de la mancha urbana hacia el periurbano, destacando el eje de crecimiento hacia el sector antedicho (Figura 1). 
FIGURA 1

Área de estudio: ciudad de Formosa, provincia de Formosa, Argentina

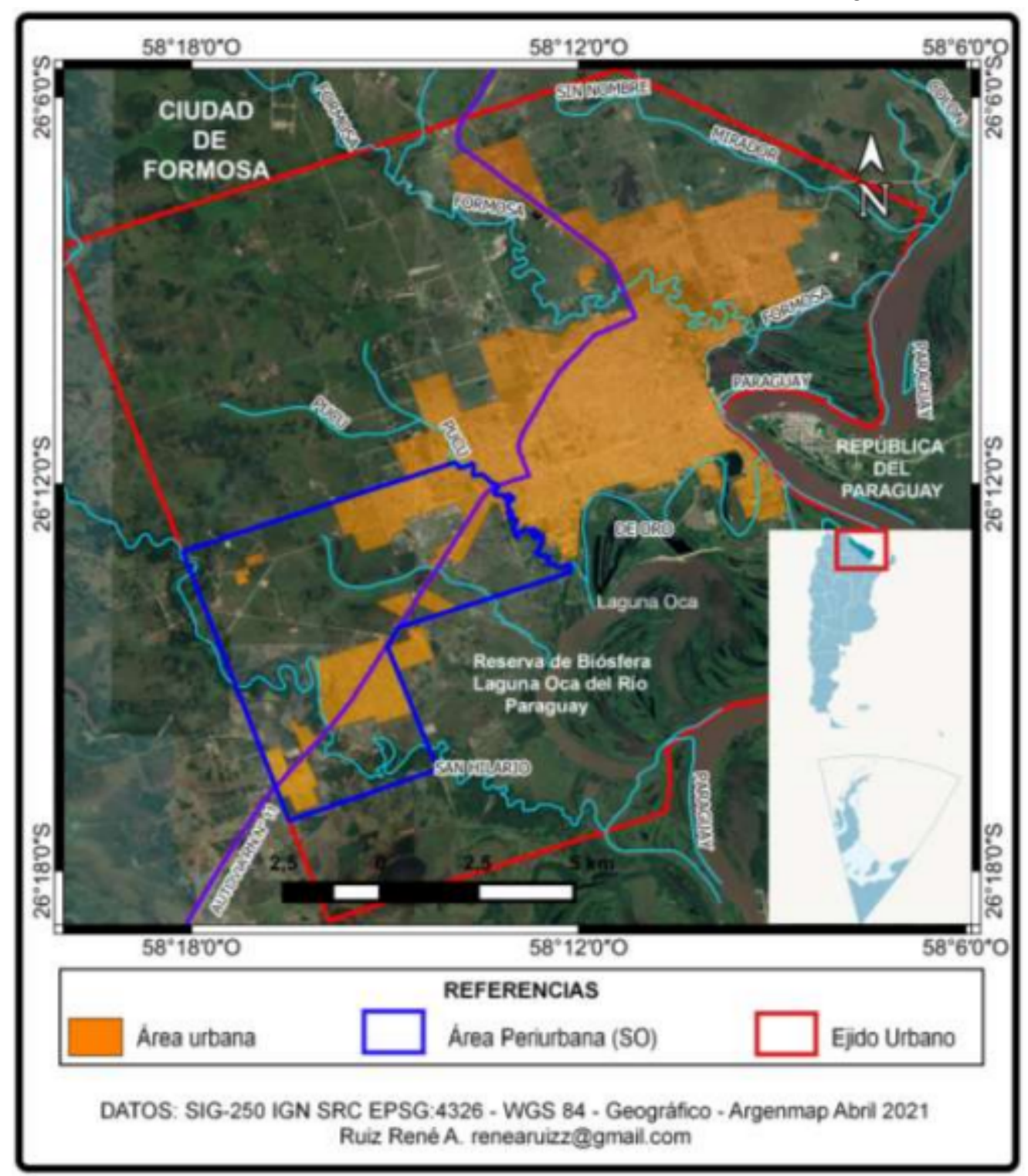

Fuente: Interpretación visual de imágenes satelitales de Google Earth ${ }^{\circ}$ (2021) y SIG250 (IGN)

\section{B) Metodología}

La metodología utilizada para llevar a cabo este estudio de caso consistió en identificar las transformaciones en el sector suroeste de la ciudad de Formosa. En una primera etapa se procedió a realizar la búsqueda de la información disponible, con visitas a diversos organismos públicos, para luego realizar el análisis documental.

En una segunda etapa, se realizaron varias salidas de campo y mediante la observación directa y el registro fotográfico se fue compilando información relevante. A partir de la utilización del Sistemas de Información Geográfica (SIG), se aplicaron distintos geoprocesos, que generaron cartografías para su posterior análisis territorial. Además, se utilizaron imágenes satelitales y otros softwares de diseño gráfico para generar cartografías, con las cuales establecer una comparación y reconocer las transformaciones del espacio geográfico desde el año 2000 al 2020. Así, se aprecia cómo fue el proceso de expansión de la mancha urbana 
sobre los ámbitos rurales, y el crecimiento del uso del suelo residencial, en el sector suroeste de la ciudad de Formosa.

Dicho trabajo se complementó con la información del servicio web del Sistema de Información Territorial (SIT Catastral v2) y la Infraestructura de Datos Espaciales (IDE) de la Dirección General del Catastro Territorial de la provincia de Formosa, mediante el cual se pudo procesar información georreferenciada y actualizada sobre el ejido municipal, lotes rurales, manzanas, parcelas, espacios vacíos, infraestructura, etcétera.

\section{c) Resultados y discusión}

\section{EL PERIURBANO Y SUS TRANSFORMACIONES TERRITORIALES EN EL SECTOR SUROESTE}

La ciudad de Formosa, en los últimos años, se ha expandido de forma acelerada y acentuada sobre los espacios naturales circundantes, superando sus antiguos limites administrativos o ejido municipal.

Estos nuevos espacios corresponden a áreas periurbanas, las que son consecuencia del continuo proceso de expansión de la ciudad sobre el área rural, que se va integrando a los límites de la ciudad. El aumento de la urbanización hacia estos territorios está relacionada con la construcción de viviendas en las afueras del núcleo urbano, lo que conlleva un desarrollo poco ordenado. La necesidad de contar con una vivienda lleva a muchas familias a asentarse en espacios naturales poco aptos para habitar o en lugares no habilitados, con construcciones precarias.

Según los registros de la comuna, en los primeros años del siglo XXI había un total de 29 asentamientos irregulares, las cuales se ubicaban en áreas periurbanas de la ciudad. Estas familias se caracterizaban por presentar desigualdades sociales, lo que hacía muy difícil el acceso al espacio urbano. En el año 2004 el municipio puso en marcha un plan de Reordenamiento Urbano, en el que pretendía lograr, en una primera etapa, una integración física y social de 10 asentamientos. Para ello, se realizaron las mensuras de los terrenos con la apertura de calles y se procedió a la adjudicación de las parcelas de 10x30 m, para construir módulos habitacionales, y al tendido de los servicios de energía eléctrica y agua potable. Se hicieron las reservas para espacios de áreas verdes, de esparcimiento y equipamiento comunitario; con el amanzanamiento y parcelamiento se logró continuar con la trama urbana, con lo cual se mejoraron las condiciones de hábitat y los vínculos sociales preexistentes de los adjudicatarios (Municipalidad de Formosa, 2004).

En el año 2007 se presentó un plan de desarrollo y ordenamiento urbano sustentable para la ciudad de Formosa (Figura 2), en el que se abordó la complejidad de esta urbe a través de un equipo especializado y mediante diversos talleres participativos de la comunidad en general (Centros de Estudios y Proyectación del Ambiente CEPA, 2017). 
FIGURA 2

Plan de desarrollo y ordenamiento urbano sustentable de la ciudad de Formosa año 2007

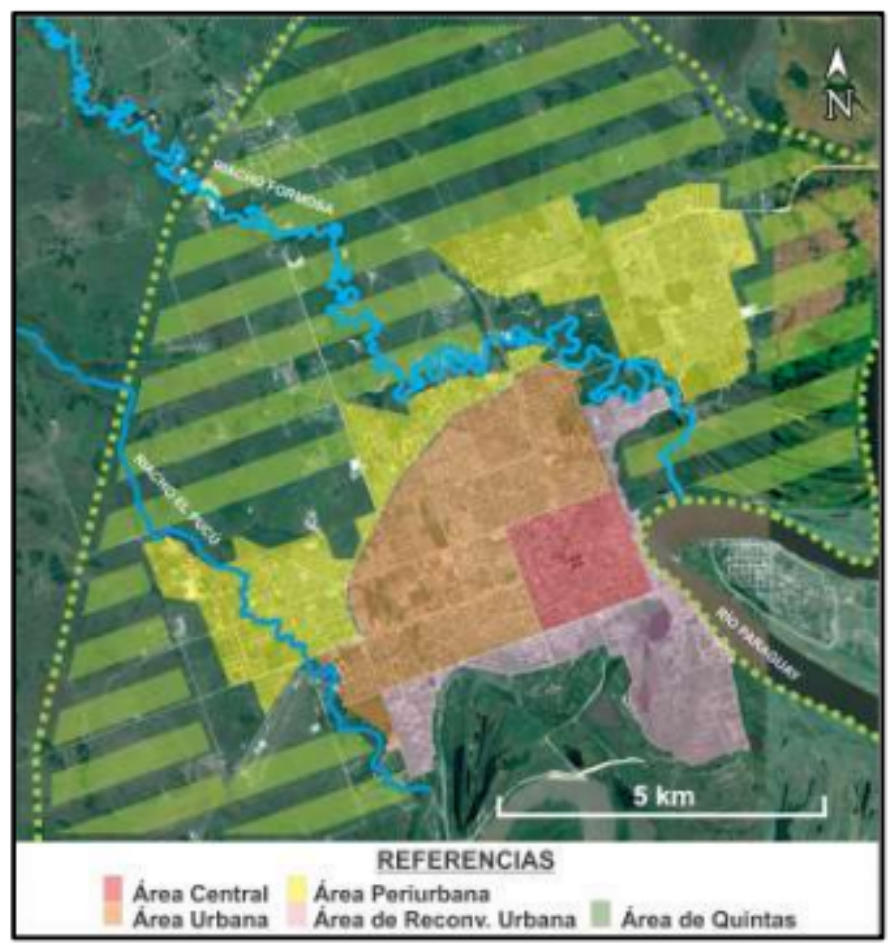

Fuente: Elaboración en base a datos del Centros de Estudios y Proyectación del Ambiente (CEPA).

$\mathrm{Al}$ analizar el estado de situación, y con el objetivo de poner en práctica un proyecto de ordenamiento urbano, se logró: la definición del límite urbano a consolidar, un proyecto integral contra inundaciones, la consolidación de la Reserva de Biosfera Urbana (RBU), la creación de vías verdes en la trama vial principal, implementar nuevas modalidades para la construcción de viviendas de interés social y crear un cinturón de quintas de interés social, entre otros aspectos analizados. A partir de lo expuesto anteriormente, se logró elaborar un Modelo Espacial Urbano.

La expansión urbana de la ciudad de Formosa a lo largo de su historia ha estado condicionada por los ambientes naturales y el factor antrópico. Esta ciudad se encuentra emplazada en un área de interfluvios y su expansión está condicionada por barreras naturales como el río Paraguay y los Riachos Formosa, El Pucú, San Hilario y Salaberry.

En este sentido, para analizar los cambios territoriales en el sector suroeste de la ciudad de Formosa se propone la clasificación de Vigliocco y Meda (1991) sobre las áreas residenciales y su grado de consolidación (consolidada, a consolidar y sin consolidar) en espacios urbanos.

Estableciendo un corte temporal entre los años 2000 y 2020, se puede observar, en los primeros años del siglo XXI, un crecimiento espacial en la periferia de esta ciudad. En un principio, el crecimiento urbano del sector suroeste estaba condicionado por el Riacho El Pucú, que se constituía como un límite natural, y en aquella época se empezaban a configurar los primeros asentamientos en los barrios: Los Quebrachos, ubicado en el Lote Rural 113, Fracción A-Código 130, Sagrado Corazón de María (L.R. 132-Ord. 2320/90Código 12) y 16 de Julio (L.R. 114-Ord. 4352/00); en dichas áreas se podían observar algunas construcciones de viviendas en formas dispersas, con mensuras, parcelamientos, apertura de calles y los proyectos para la prestación de servicios esenciales.

Hacia el año 2000 (Figura 3) se podían observar dos asentamientos fuera de los límites del ejido urbano (este fue delimitado en el año 1976), que se caracterizaban por realizar actividades rurales. El primero se llama Congregación Cristiana Pueblo de Dios o Trinidad Divina, ubicado en el lote rural $\mathrm{N}^{\circ} 221$, que es de 
su propiedad, y que comprende unas 86 hectáreas aproximadamente; en el año 2001 los registros censales indican que poseía un total de 283 habitantes (Censo Nacional de Población, Hogares y Viviendas, 2001). Esta comunidad se encuentra distante unos $11 \mathrm{~km}$ del casco histórico de la ciudad y se accede por caminos de tierra sin compactar, por lo que en épocas de lluvias se hace imposible transitar.

FIGURA 3

Periurbano de la ciudad de Formosa, sector suroeste año 2000

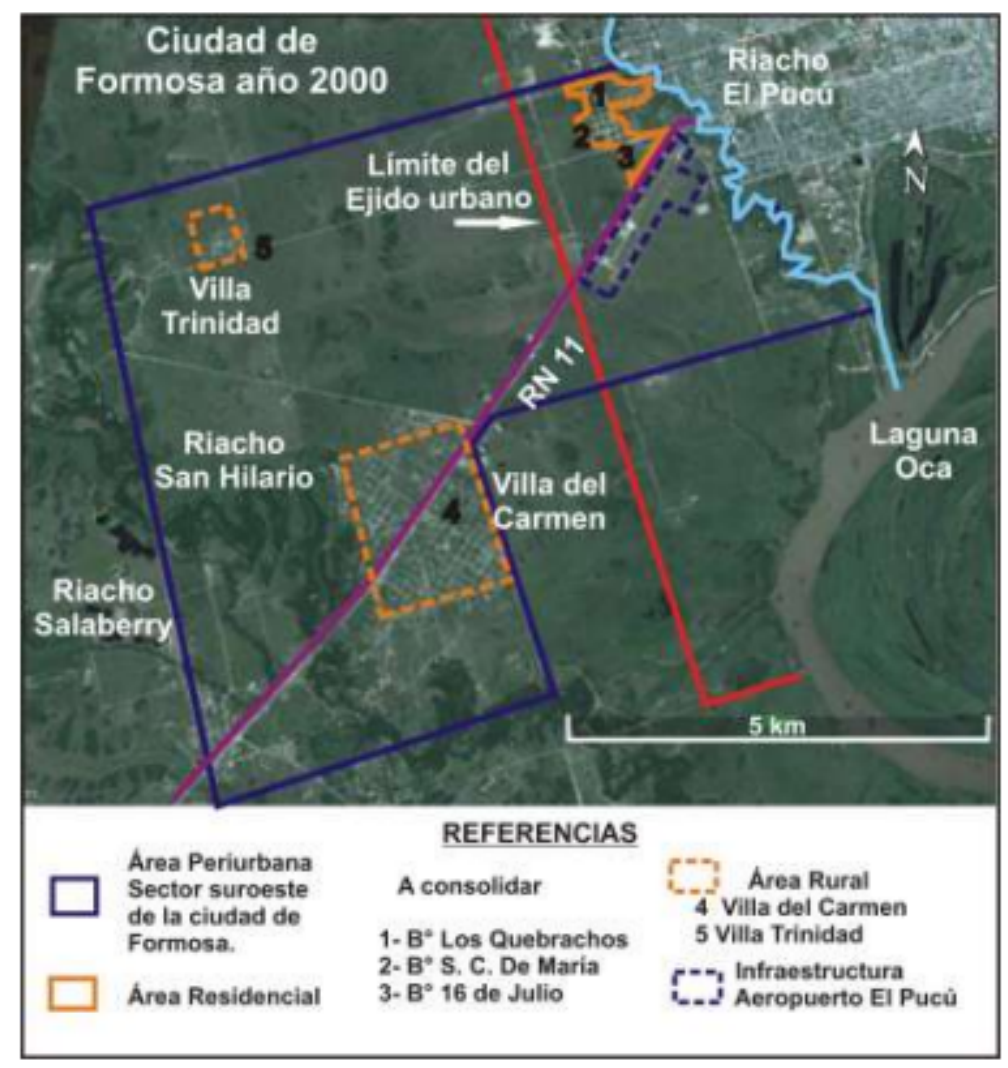

Fuente: Interpretación visual de imágenes satelitales de Google Earth ${ }^{\circledR}$ (2020) y trabajo de campo

El otro asentamiento de análisis es Villa del Carmen. Según los datos obtenidos, hacia el año 1960 este sector era un área rural donde existía un predominio de establecimientos ganaderos y producción lechera. En la década del 70 se inició un proceso de loteos sin los servicios esenciales, que llegó a alcanzar una superficie aproximada de 400 hectáreas. Se encuentra distante a $13 \mathrm{~km}$ aproximadamente del casco céntrico, con pequeñas agrupaciones de edificaciones, espacios vacíos y una población estimada en 1.885 habitantes aproximadamente, según los datos del Censo Nacional de Población, Hogares y Viviendas 2010.

En esos años, se encontraba fuera de los límites administrativos del ejido municipal de la ciudad de Formosa, y sus residentes tenían tres características fundamentales: a) realizaban actividades rurales para satisfacer sus necesidades básicas; b) algunos de los pobladores se desplazaban en forma cotidiana a la ciudad para trabajar; c) personas que vivían en la ciudad adquirían parcelas para la construcción de casas de fines de semana con piletas, para pasar el día. Estas características se pueden asociar a un territorio periurbano, que se vincula con los límites de la región urbana y con espacios predominantemente rurales donde viven personas que trabajan en la ciudad (Precedo Ledo, 2004).

En cuanto a la infraestructura, por un lado, se puede destacar el Aeropuerto Internacional de Formosa "El Pucú" (L.R. 114-Dec. 21, 16/12/87), inaugurado en febrero de 1968 y ubicado a 7 km del centro de la ciudad. Por otro lado, la Ruta Nacional $N^{\circ} 11$, principal vía de comunicación que se inicia en Rosario, 
atraviesa la ciudad de Formosa y termina en el Puente Internacional San Ignacio de Loyola, en la frontera con la República del Paraguay.

Con el pasar del tiempo, las realidades urbanas y las necesidades de sus habitantes de contar con un techo digno han hecho que se ocupen estos espacios en el periurbano, lo que desbordó los límites administrativos y transformó el medio natural. La ampliación del ejido urbano en el año 2015 permitió sumar al municipio un total de 33.144 hectáreas aproximadamente, las cuales pueden ser apreciadas en las figuras 3 y 4 , incluyendo diversos barrios que carecían de los servicios públicos y se encontraban en zonas de vulnerabilidad social: los barrios Villa del Carmen, Nueva Pompeya, Santa Isabel, un sector de La Nueva Formosa y todo el territorio intermedio que se incluye dentro de esta nueva franja.

En la actualidad, año 2020, se puede ver una expansión de la ciudad hacia la periferia (Figura 4), en la que se destacan nuevas áreas residenciales consolidadas, como los barrios Sagrado Corazón de María, 16 de Julio, la Nueva Formosa (L.R. 131, 132, 149 y 150). Este último barrio constituye un proyecto de desarrollo urbanístico de carácter estatal. También existen otros espacios en construcción, en los cuales se observan las mensuras de las parcelas, como en el caso del barrio Nueva Italia, que se pueden adquirir a través del mercado inmobiliario.

\section{FIGURA 4}

Ocupación del espacio periurbano en el sector suroeste, año 2020

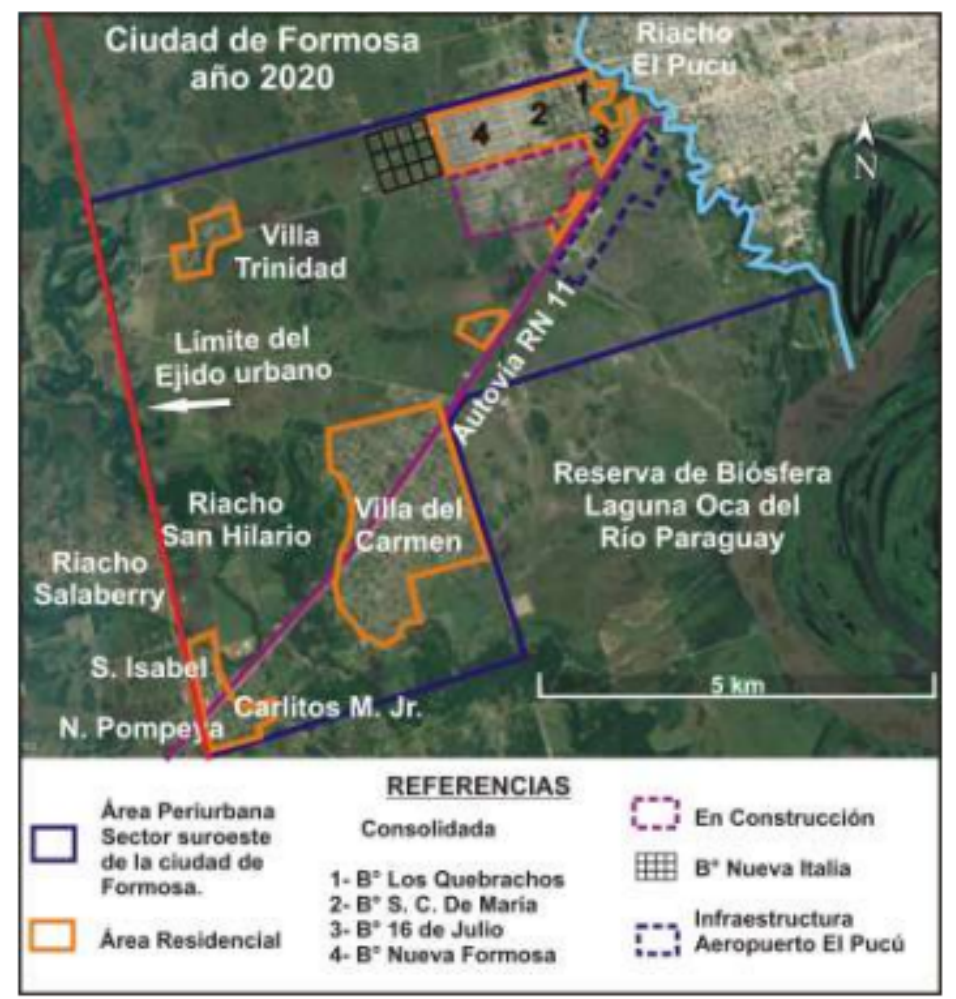

Fuente: Interpretación visual de imágenes satelitales de Google Earth $^{\circ}(2020)$ y trabajo de campo

Además, se encuentra un asentamiento llamado Villa Trinidad, con acceso por la Av. Los Pumas y siguiendo el eje de la Autovía de la Ruta Nacional 11 (en la actualidad está en construcción), donde se observan sectores con edificaciones a ambos lados de esta vía de comunicación. También presenta un aumento del espacio ocupado por viviendas en Villa del Carmen y en el límite del ejido municipal, la conformación de nuevos barrios, como Nueva Pompeya, Santa Isabel y Carlitos Menem Junior.

En la siguiente cartografía (Figura 5) se pueden observar los usos del área residencial según su grado de consolidación: a) consolidada, con los barrios que tienen una ocupación mayor al $75 \%$ de su espacio y cuentan 
con todos los servicios; b) a consolidar: entre el 50 y $75 \%$ se encuentran habitados y cuentan con más de un servicio; c) sin consolidar: son áreas que se encuentran ocupadas en un rango menor al $50 \%$ y cuentan con un servicio o con ninguno.

FIGURA N 5

Grado de consolidación de las áreas residenciales del sector suroeste

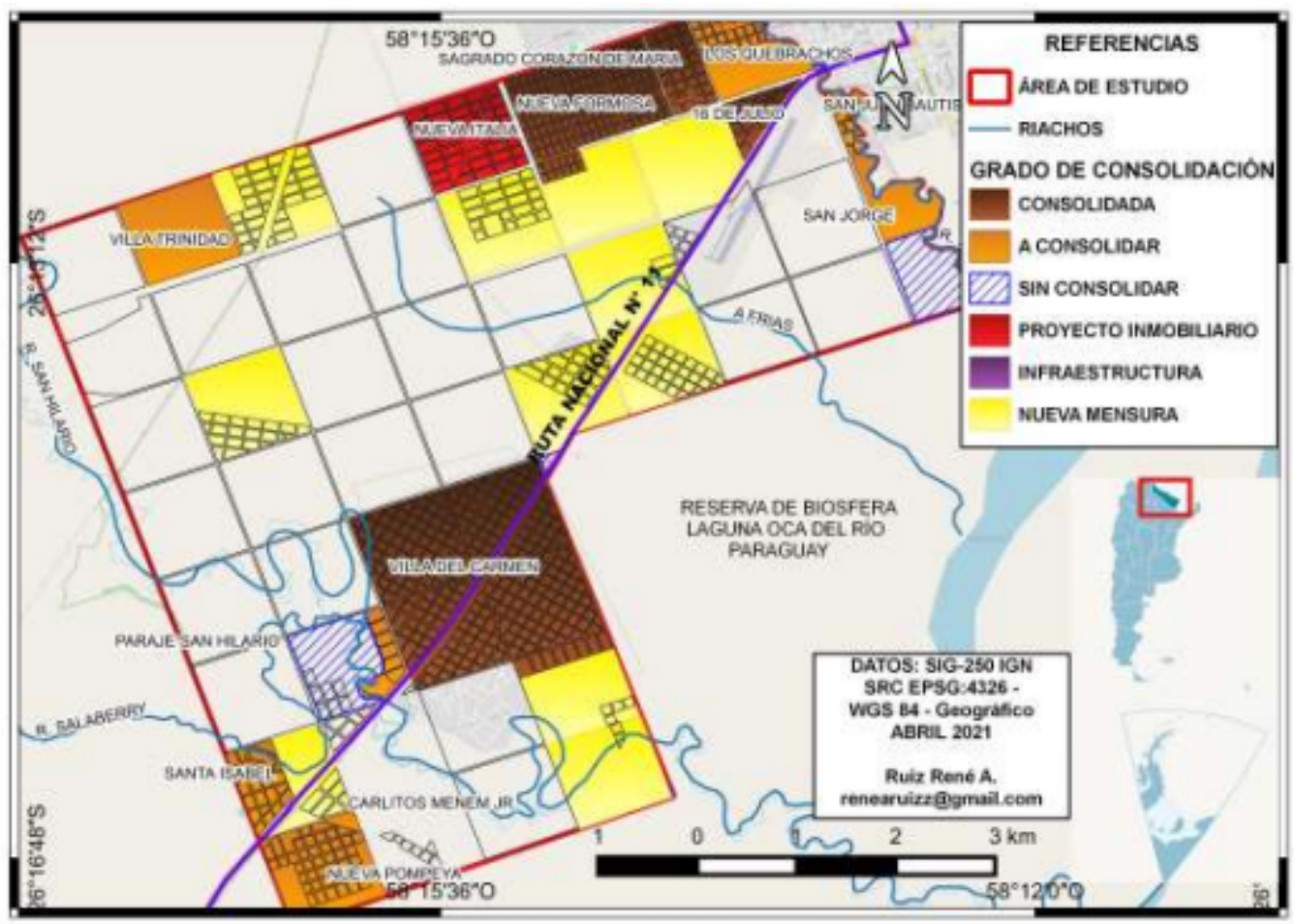

Fuente: Elaboración propia sobre la base de trabajos de campo, interpretación visual de imágenes satelitales de Google Earth ${ }^{\circ}$ (2021) y SIG250 (IGN)

\section{Caracterización de las diferentes formas de PRODUCción habitacional EN EL PERIURBANO}

El crecimiento urbano hacia la periferia se viene desarrollando a causa de un aumento del proceso de urbanización, por el cual el SO es el territorio con mayor transformación de su espacio natural. El uso del suelo residencial es el que se destaca en esta área de estudio, en la cual la vivienda construida y los servicios con que cuenta constituyen el hábitat donde sus residentes realizan todas sus actividades sociales.

En esta línea de análisis, se caracterizarán las formas de producción habitacional actual, tomando como referencia la clasificación elaborada por Barreto, Abildgaard, Depettris y Puntel (2017), que realiza una identificación espacial de agrupamientos de viviendas homogéneas generadas por tres tipos de formas de producción: informal, estatal y privada.

Informal: Se refiere a los agrupamientos de viviendas a consolidar que tuvieron este origen y que pudieron o no recibir algún tipo de intervención del Estado para consolidar o mejorar su hábitat. El Barrio Los Quebrachos posee un sector con todas estas características, donde unas 390 familias viven en unas dos hectáreas aproximadamente. Se puede observar (Figura 6) la construcción de viviendas sin un orden establecido. Además, se encuentra próximo al Riacho El Pucú y en épocas de abundantes precipitaciones se transforma en un área de vulnerabilidad hídrica, pues está por fuera del anillo de defensa de la ciudad y es considerada como una zona no apta para la urbanización. 
FIGURA 6

Tipos de viviendas en las diversas formas de producción habitacional

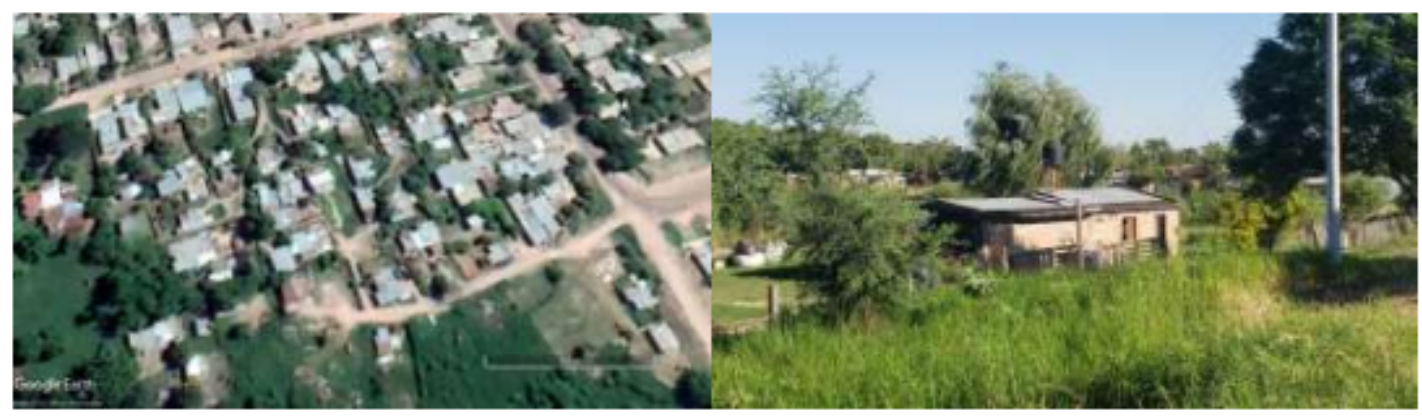

Fuente: Interpretación visual de imágenes satelitales de Google Earth ${ }^{\circledR}$ y fotografía tomada en el barrio Los Quebrachos, abril 2021

Estatal: Son los agrupamientos de viviendas consolidadas y construidas por el Estado (Figura 7), a través de empresas privadas o cooperativas de trabajo. Mediante la inversión pública se pretende brindar una solución habitacional a numerosas familias y un ejemplo de ello es el Barrio la Nueva Formosa. Este barrio es un proyecto de desarrollo urbanístico entre la provincia y el municipio que busca cubrir la demanda habitacional, llevado a cabo por el Instituto Provincial de la Vivienda (I.P.V), con fondos monetarios provenientes del Fondo Nacional de la Vivienda (FONAVI).

La construcción de estas viviendas se viene desarrollando desde el año 2005 en varias etapas y al mes de diciembre del 2020 se habían entregado 2700 unidades habitacionales, sobre un total de 5400 unidades, planificadas para unas 30.000 personas aproximadamente.

\section{FIGURA 7}

Tipos de viviendas en las diversas formas de producción habitacional

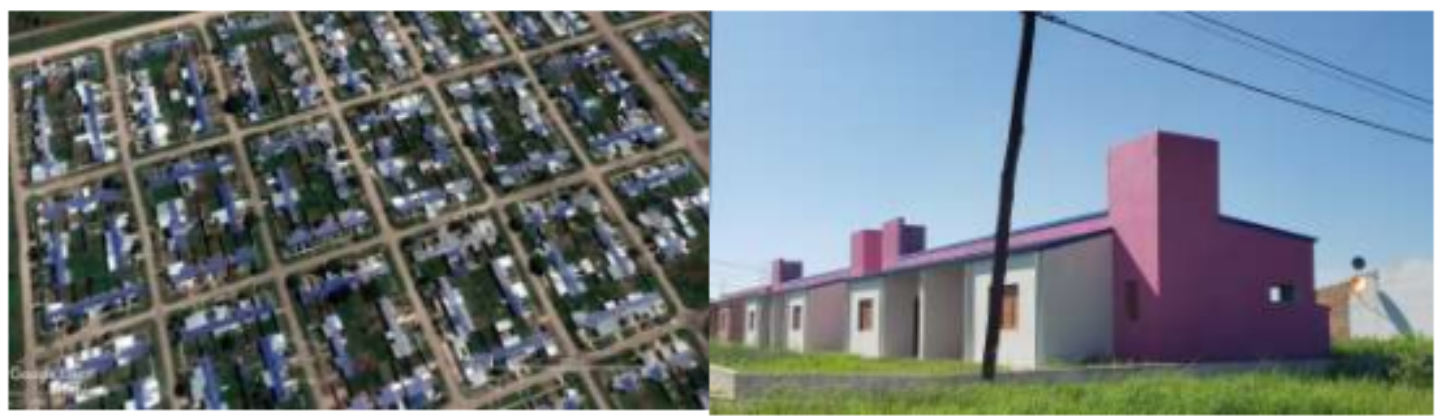

Fuente: Interpretación visual de imágenes satelitales de Google Earth. Imagen del barrio la Nueva Formosa, abril 2021

Privada: Se refiere a todos los agrupamientos que tuvieron este origen, hayan sido promovidos por desarrolladores inmobiliarios o por sus propietarios. La configuración del Barrio Villa del Carmen se inició en el año 1960 aproximadamente, era un casco de estancia en un área netamente rural, con numerosos establecimientos ganaderos. Desde el año 2000 se observa un aumento del espacio urbanizado, el cual se encuentra distante a unos $13 \mathrm{~km}$ del casco céntrico de la ciudad y se comunica por la autovía de la ruta Nacional $\mathrm{N}^{\circ} 11$. Según el último censo, posee una población estimada en 1.885 habitantes (INDEC, 2010) y está superando las 400 hectáreas de superficie urbanizada, donde se pueden apreciar las manzanas bien delimitadas, con pequeñas agrupaciones de viviendas que incluyen sectores de esparcimiento: espacios verdes con juegos para niños, piscinas, canchas de tenis y futbol, entre otros. Los residentes de este barrio se caracterizan por: a) realizar algunas actividades rurales, b) sus pobladores se desplazan en forma cotidiana a la ciudad para trabajar y c) hay habitantes que viven en la ciudad, pero que adquirieron una parcela y construyeron casas de fin de semana o poseen complejos de cabañas para ir a pasar el día (Figura 8). 


\section{FIGURA 8}

Tipos de viviendas en las diversas formas de producción habitacional

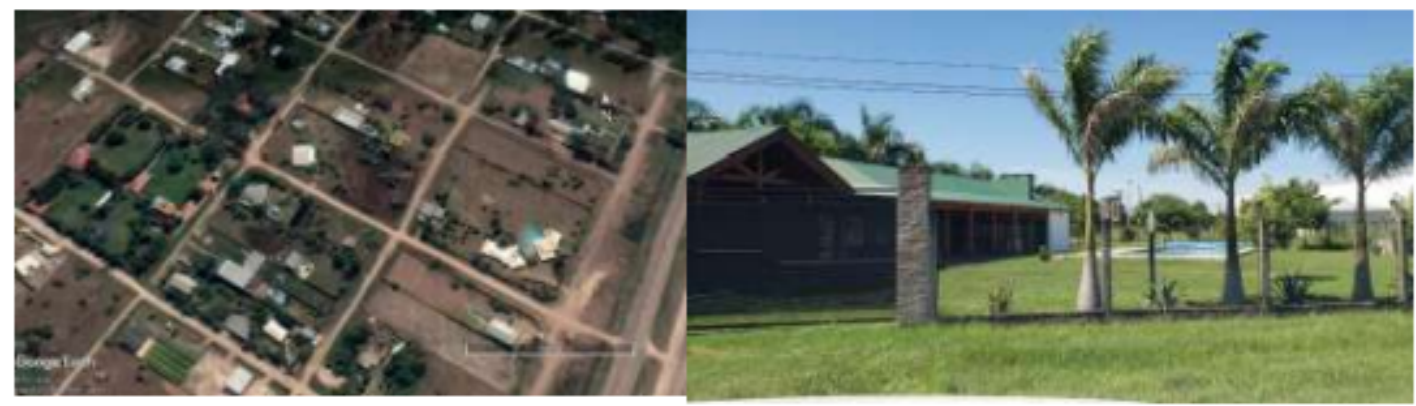

Fuente: Interpretación visual de imágenes satelitales de Google Earth ${ }^{\circledR}$ y fotografía tomada en el barrio Villa del Carmen, abril 2021

Estas tres formas de producción habitacional en el periurbano $(\mathrm{SO})$ ponen sobre relieve una importante fragmentación física y socioeconómica del espacio residencial, ya que, al vivir en la periferia, existe una mayor dependencia de algún medio de movilidad (automóviles, autobuses, motos, bicicletas) para desplazarse hasta el trabajo, en el que también se puede observar un proceso de segregación espacial.

\section{D) Conclusiones}

En el período analizado (2000-2020) se advierte que la ciudad de Formosa presenta un crecimiento hacia los espacios con incipientes o aisladas edificaciones, sumando espacios rurales circundantes o localidades próximas. El sector suroeste es el de mayor transformación de sus condiciones naturales, a causa de una marcada urbanización con fines residenciales.

$\mathrm{Al}$ analizar las imágenes satelitales de principios del siglo XXI, se observa un área de interfluvios, con Riachos como El Pucú que actuaban como una barrera natural al crecimiento de la ciudad. Por un lado, la población se fue asentando y edificando en los terrenos más altos, y así se fueron conformando los barrios Los Quebrachos, Sagrado Corazón de María, 16 de Julio. Por otro lado, había grandes espacios despoblados, debido a la existencia de canales naturales de desagües o terrenos con pendientes bajas, propensas a inundaciones en épocas de constantes lluvias. Mientras que en las afueras del ejido municipal, se aprecian pequeños agrupamientos de viviendas en áreas rururbanas, como ser la Congregación Cristiana Pueblo de Dios o Trinidad Divina y el $\mathrm{B}^{\circ}$ Villa del Carmen, distantes $13 \mathrm{~km}$ aproximadamente del casco céntrico, y que desarrollan actividades rurales.

En la actualidad, el espacio periurbano del sector suroeste presenta profundas transformaciones territoriales, en las que se destaca el uso del suelo residencial con diferentes grados de consolidación. Se observan áreas residenciales consolidadas como los barrios Sagrado Corazón de María, 16 de Julio, la Nueva Formosa. Este último barrio constituye un proyecto de desarrollo urbanístico de carácter estatal, distante unos $10 \mathrm{~km}$ del casco céntrico. Además, se identificaron otros espacios en construcción, como el barrio la Nueva Italia, en los cuales se observan las mensuras de las parcelas y se puede acceder a él adquiriendo en el mercado inmobiliario.

En esta área periurbana existía una predominancia de actividad ganadera, pero con la ampliación del ejido urbano en el año 2015 el municipio capitalino incorporó nuevos territorios rurales a su administración. Como consecuencia, esos campos empezaron a lotearse y mensurarse, en algunos casos como proyectos inmobiliarios.

A raíz de esta expansión de los límites administrativos del municipio, se incorporaron nuevas áreas pobladas, como Villa Trinidad, Villa del Carmen, Nueva Pompeya, Santa Isabel, Carlitos Menem Junior, con un crecimiento de su zona urbanizada que sigue el eje de la Autovía de la Ruta Nacional 11. 
Estas nuevas áreas incorporadas presentan espacios despoblados, en los que se perciben zonas bajas o de riesgo hídrico ambiental, poco aptas para la urbanización. En cuanto a las formas de producción habitacional, actualmente se pueden identificar tres clases, de agrupamientos: informal, estatal y privada. En ellas se observa una importante fragmentación física y socioeconómica del espacio residencial, ya que, al vivir en la periferia, las personas tienen una mayor dependencia de algún medio de movilidad (automóviles, autobuses, motos, bicicletas) para desplazarse hasta el centro de la ciudad, donde trabajan, o vienen hacia la periferia a descansar en sus casas de fin de semana.

\section{ReFERENCIAS}

Alberto, J. A. (2004). Caracterización de los usos del suelo de un espacio periurbano del Gran Resistencia. Revista Geográfica Digital, 1(1), 01-13. Recuperado de https://revistas.unne.edu.ar/index.php/geo/issue/view/308/sh owToc

Barreto, M., Abildgaard, E., Depettris, N. y Puntel, L. (2017). Unidades espaciales residenciales homogéneas como factor de fragmentación social. En Girodano, M. (Comp.), Actas del XXXVI Encuentro de Geohistoria Regional (pp. 311-320). Resistencia, Argentina: Instituto de Investigaciones Geohistóricas (CONICET), Resistencia.

Benedetti, A. (2020). Fronteras y escalas: definiciones y relaciones. En A. Hernández Hernández (Coord.), Puentes que unen y muros que separan. Fronterización, securitización y procesos de cambio en las fronteras de México y Brasil (pp. 45-62). Tijuana: El colegio de la Frontera Nore, A. C.

Blanco, J. (2015). Territorio, circulación y redes: articulaciones y tensiones. En M. Arroyo Y R. Cruz (Orgs.) Território e circulação. A dinâmicacontraditória da globalização (pp. 15-36). São Paulo: Annablume.

Municipalidad de Formosa (2004). Plan de reordenamiento urbano. Ciudad de Formosa, Argentina.

Feito, M. C. y Barsky, A. (2020). Periurbano. En J. Muzlera y A. Salomón (Eds.), Diccionario del Agro Iberoamericano (pp. 907-918). Buenos Aires: TeseoPress Design.

Centros de Estudios y Proyectación del Ambiente CEPA (2017). Antecedentes. La Plata.

Frediani, J. C. (2009). Las nuevas periferias en el proceso de expansión urbana. El caso del partido de La Plata. Geograficando. Revista de Estudios Geográficos, 5(5), 103-125. Recuperado de http://www.memoria.fahce.unlp .edu.ar/art_revistas/pr.4445/pr.4445.pdf

Instituto Nacional de Estadística y Censos INDEC (2010). Censo Nacional de Población, Hogares y Viviendas 2010. Recuperado de https://www.indec.gob.ar/indec/web/Nivel3-Tema-2-41.

Precedo Ledo, A. (2004). Nuevas realidades territorialespara el siglo XXI. Desarrollo local, identidad territorial y ciudad difusa. Madrid. Editorial Síntesis.

Reese, E. (2006). La situación actual de la gestión urbana y la agenda de las ciudades en la Argentina. Medio Ambiente y Urbanización, 65 (1), 3-21. Recuperado de http://www.faud.unsj.edu.ar/blogs/catedra/54/86-bibliografia-u nidad-3-reese-eduardo-2006/

Vigliocco, M. A. y Meda, R. H. (1991). Estructura urbana y uso del suelo. Aplicación a ciudades bonaerenses. Buenos Aires: Editorial Civilidad. 